\title{
Effectiveness of 6-shogaol in potentiating sevoflurane mediated neuroprotection against ischemia/reperfusion-induced brain injury via regulating apoptotic proteins and $\mathrm{PI} 3 \mathrm{~K} / \mathrm{Akt} / \mathrm{mTOR} / \mathrm{s} 6 \mathrm{~K}$ signalling and HIF-1 $\alpha / \mathrm{HO}-1$ expression
}

\author{
Junqiao Zhang ${ }^{1}$, Yongxiang $\mathrm{Li}^{1}$, Yicai Li ${ }^{1}$, Hongwei Liu ${ }^{1}$, and Mengmeng Zhang ${ }^{1}$ \\ ${ }^{1}$ Affiliated Hospital of Weifang Medical University
}

October 8, 2020

\begin{abstract}
Purpose: The current research has been intended to evaluate the impacts of 6-shogaol in rodent model of ischemic-reperfusion induced- brain injury and also assessed whether 6-shogaol enhanced sevoflurane's neuroprotective effects. Methods: IschemicReperfusion (I/R) injury was induced by middle cerebral artery occlusion (MCAO) method in Sprague-Dawley rats. A separate group of animals was exposed to sevoflurane (2.5\%) post-conditioning for $1 \mathrm{~h}$ immediately after reperfusion. 6 -shogaol (25 mg or $50 \mathrm{mg} / \mathrm{kg}$ body weight) was orally administered to treatment group rats for 14 days and then subjected to I/R. Results: 6-shogaol treatment along with/without sevoflurane post-conditioning reduced the number of apoptotic cell counts, brain edema and cerebral infarct volume. The western blotting analysis revealed a significant stimulation of the PI3K/Akt/mTOR signal pathway. RT-PCR and western blotting studies revealed improved expressions of HIF-1 $\alpha$ and HO-1were also noticed at both gene level and protein levels as determined by. I/R induced neurological deficits were also alleviated on sevoflurane postconditioning with/without 6-shogaol treatment. Conclusion: The study's findings reveal that pre-treatment with 6-shogoal enhanced the neuroprotective properties of sevoflurane post-conditioning, illustrating the efficacy of the compound against I/R injury. 6-Shogaol thus could be investigated further for cerebral protection following I/R.
\end{abstract}

\section{Hosted file}

Manuscript.pdf available at https://authorea.com/users/365318/articles/485465-effectivenessof-6-shogaol-in-potentiating-sevoflurane-mediated-neuroprotection-against-ischemiareperfusion-induced-brain-injury-via-regulating-apoptotic-proteins-and-pi3k-akt-mtors6k-signalling-and-hif-1\%CE\%B1-ho-1-expression 

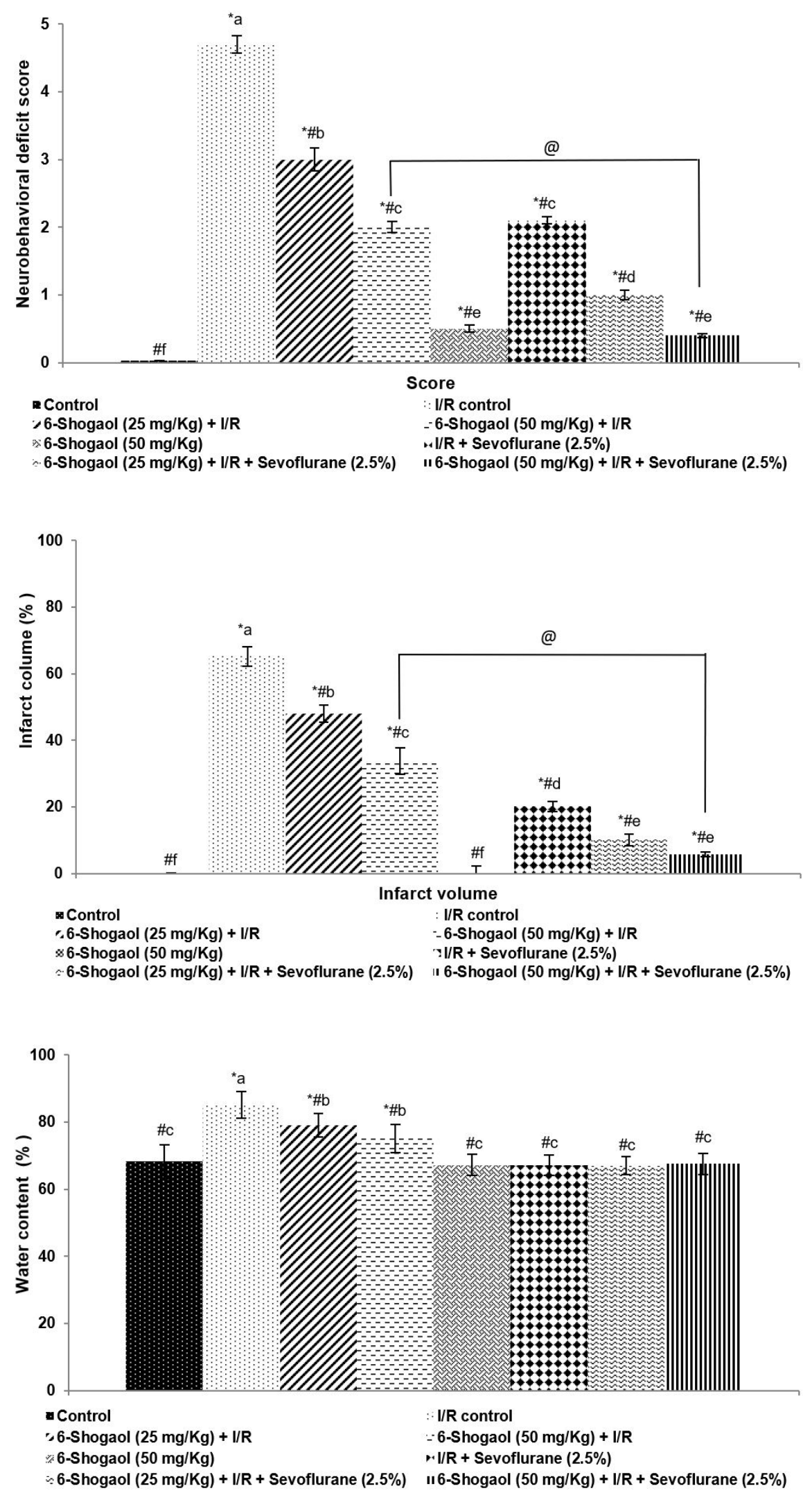

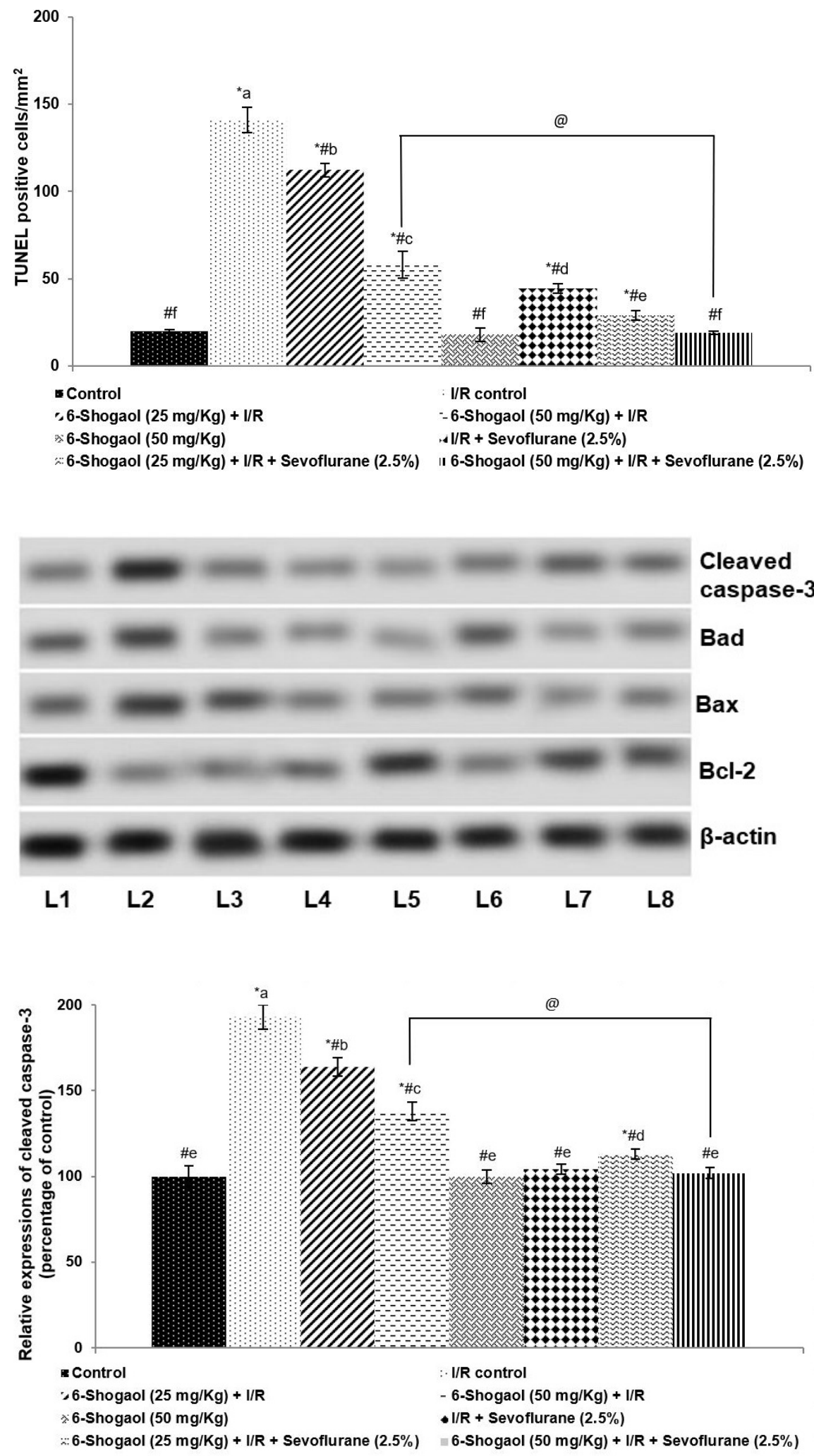

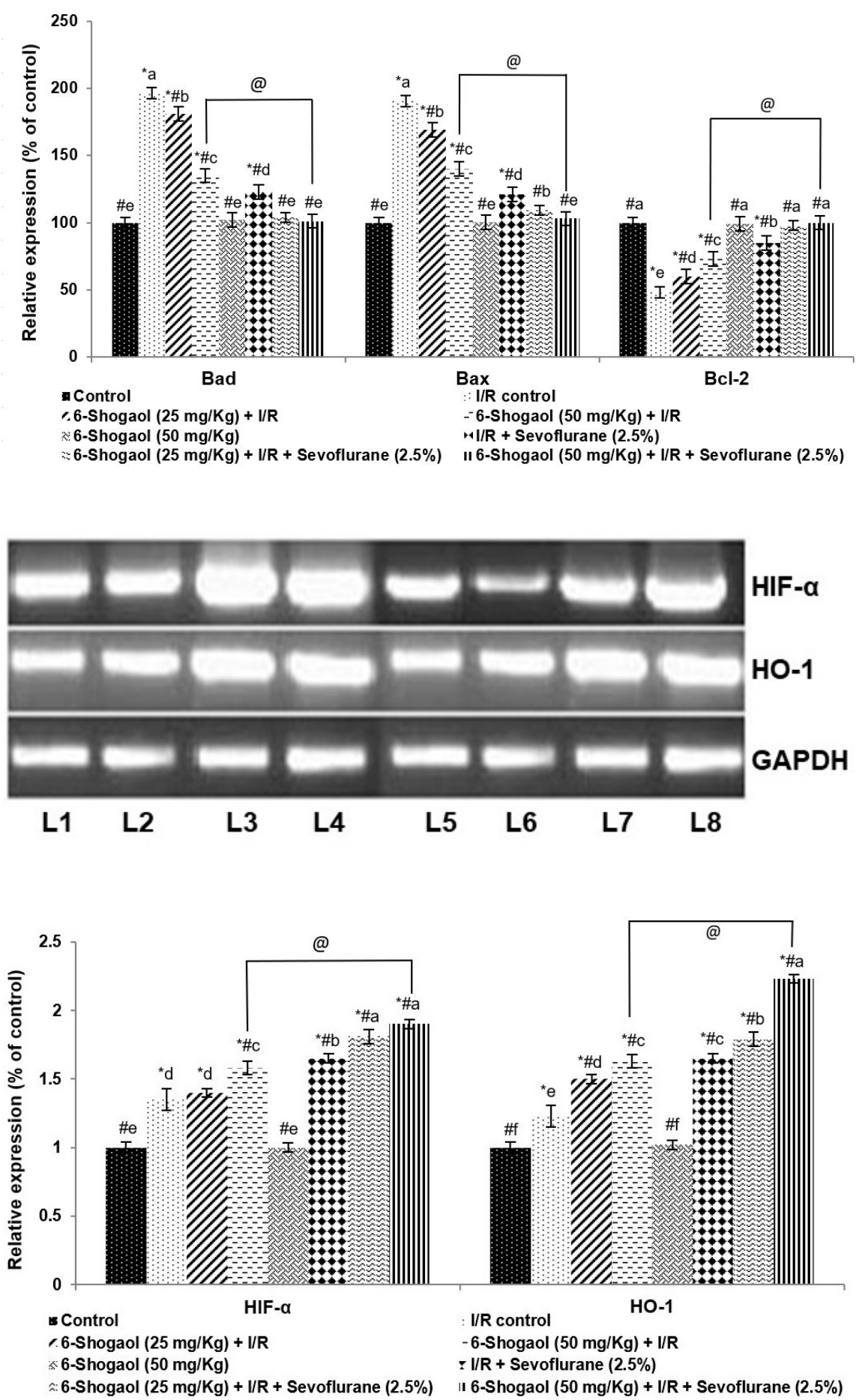

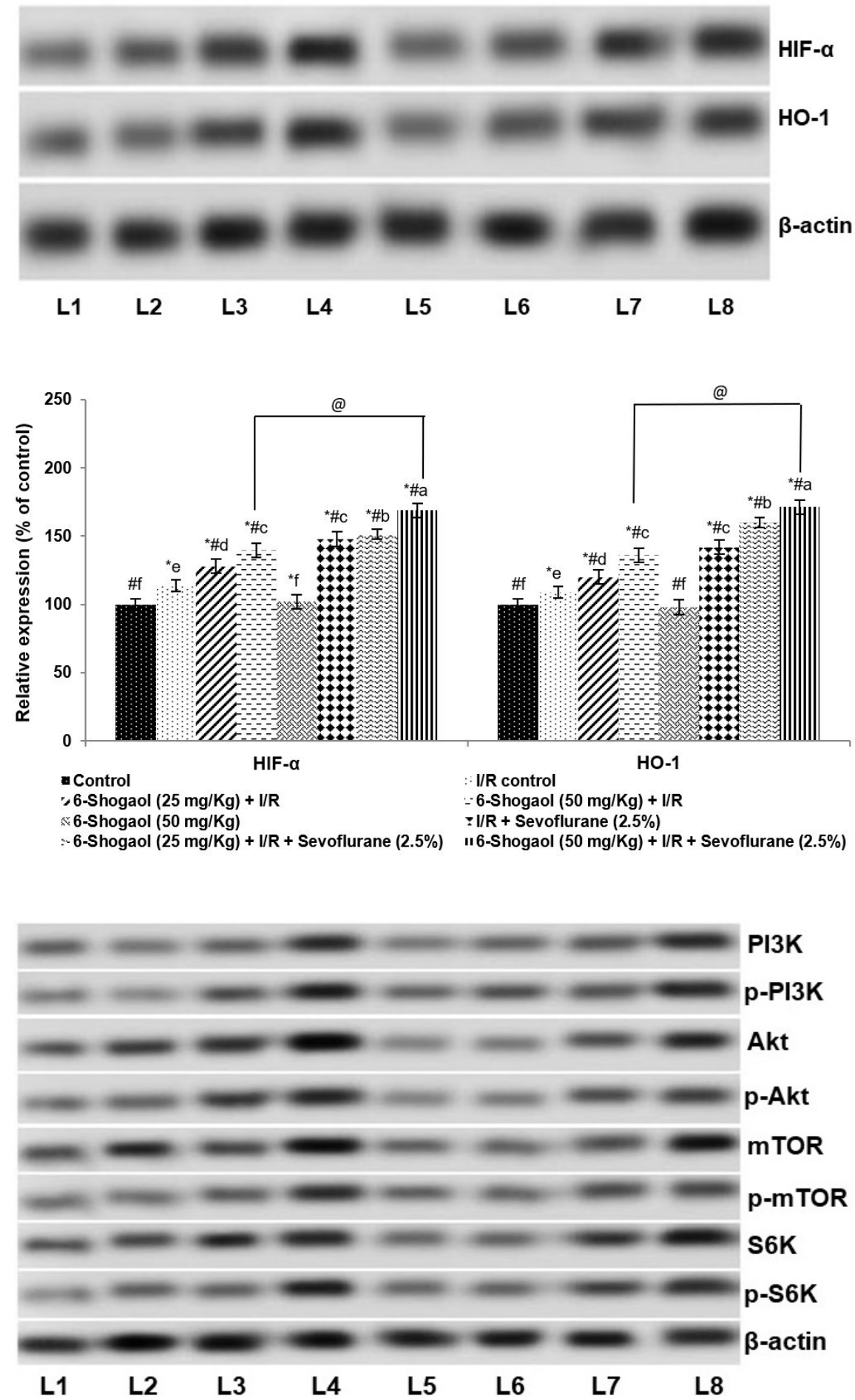

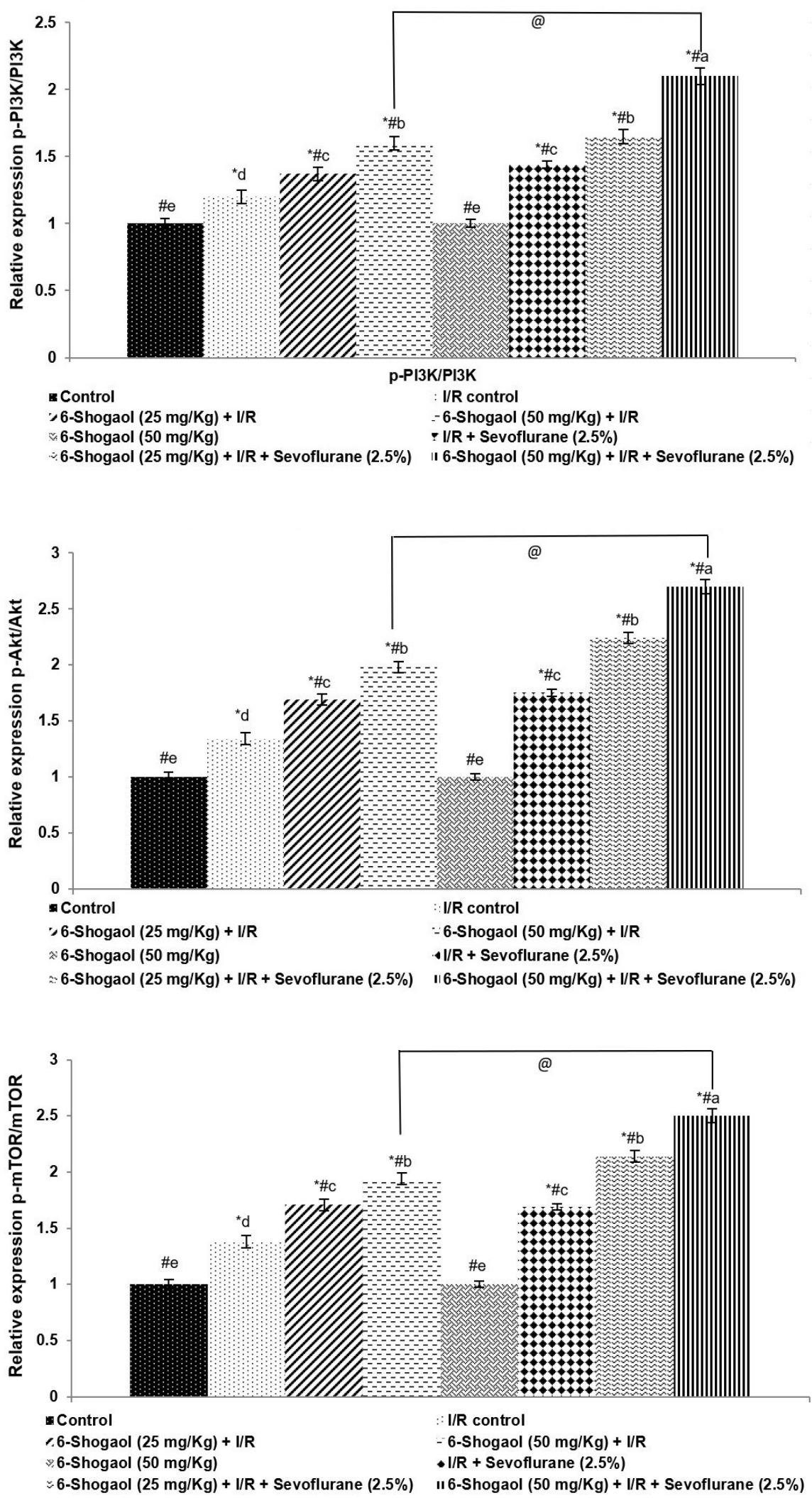